\title{
Determinants of the Declining Share of Agricultural Labour Force to Total Labour Force in Pakistan
}

\author{
Khalid Hameed SheIKH and Zafar IqBaL*
}

\section{INTRODUCTION}

The agricultural labour force in Pakistan has been increasing rapidly due to population growth as well as a declining mortality rate. However, the share of the agricultural labour force to total labour force has been decreasing. The objective of this paper is to search for the factors responsible for this decline. The period covered is from $1959-60$ to $1986-87$.

The development process is characterised as one which brings about a fundamental change in the structure of an economy. In this process, labour is shifted from low productivity areas, such as agriculture, to high productivity areas, such as the manufacturing, construction and transport sectors. The share of value added of agriculture in Gross Domestic Product (GDP) has declined from 46 percent in 1959 60 to 25 percent in $1986-87$. Hence, the key determinant of declining share of agricultural labour force to total labour force $(R A L F)$ appears to be some measure of economic development.

Another important factor considered is the population density which may affect $R A L F$. In Pakistan, the number of workers involved in agriculture is increasing over time but with a fixed supply of land-land per worker is decreasing. As a result, the rural to urban spatial dispersal of population is taking place and hence, there is a decline in $R A L F$.

The real wage in the agricultural sector is increasing at a higher rate compared with the increase in the real wage in the manufacturing sector. As a result, demand for labour in the agricultural sector declines and these labour force then shift to nonagricultural occupations in search of jobs to fulfil their basic needs of life.

There appears to be a lack of consensus regarding the impact of mechanization on agriculture. [Bose and Clark (1969); Ahmed (1972) and Khan (1975)] suggest that tractor mechanization leads to a reduction in the demand for agricultural labour. On the other hand, [Inukai, (1984); Gotsch (1973); Chaudhry (1980) and Wizarat

*The authors are Research Demographer and Staff Economist, respectively at the Pakistan Institute of Development Economics, Islamabad. They are grateful to Dr Ashfaque H. Khan for his useful comments on the revised draft of this paper. This is a condensed version of the paper presented at the Fifth Annual General Meeting. 
(1982)] have argued that technological change has been of the labour-augmenting type in Pakistan. Thus, we also examine the impact of technological change on $R A L F$.

\section{METHODOLOGY AND DATA}

Five equations are specified to examine the trends of the ratio of agricultural labour force $(R A L F)$ to total labour force.

$$
\begin{aligned}
& R A L F=\alpha_{0}+\alpha_{1} R A G+\alpha_{2} P H P+\alpha_{3} K A+e \quad \ldots \quad \ldots \\
& R A L F=\gamma_{0}+\gamma_{1} P H P+\gamma_{2} K A+v \quad \ldots \\
& R A L F=\beta_{0}+\beta_{1} R A G+\beta_{2} K A+u \quad \ldots \quad \ldots \\
& R A L F=\lambda_{0}+\lambda_{1} R A G+\lambda_{2} R A M+\lambda_{3} K A+g \quad \ldots \quad \ldots \\
& R A L F=\theta_{0}+\theta_{1} R A M+\theta_{2} K A+w \quad \ldots \quad \ldots
\end{aligned}
$$

Where

$$
\begin{aligned}
& R A G=\text { Share of value added of agriculture to GDP; } \\
& P H P=\text { Population density; } \\
& R A M=\text { Ratio of real wage in agriculture to real wage in manufacturing; and } \\
& K A \quad=\text { Capital stock in agriculture. }
\end{aligned}
$$

$A$ priori, we expect a positive relationship between $R A G$ and $R A L F$. As mentioned earlier, the share of value added of agriculture in GDP is declining continuously therefore the labour force in this sector is shifting from low productivity areas to high productivity areas hence $R A L F$ is falling. As regards the use of capital in agriculture $(K A)$ we can not say anything about the sign of the coefficient with confidence because of the disagreement that prevails in this respect. Finally, for the ratio of real wage in agriculture to real wage in manufacturing $(R A M)$, we expect a negative sign to conform with the theory of demand for labour, which is a decreasing function of the wage rate.

The data used in this paper have been obtained from Government of Pakistan (1987) and are at constant prices of 1959-60. The data for real wages in agriculture and manufacturing are obtained from Naqvi, et al. (1983). Since capital stock series in agriculture is not available from any published source, we constructed the series by using the method given in Burney (1986).

\section{RESULTS}

$$
\begin{aligned}
R A L F= & \begin{array}{c}
0.24+0.45 \\
(1.75)(1.90)^{* *} \quad(0.68)
\end{array} \quad(4.25)^{*} \\
\bar{R}^{2}= & 0.83 \quad F=44.45 \quad \text { D. } W .=1.55
\end{aligned}
$$

A look at the result is sufficient to see that $R A G$ possesses positive sign and is statistically significant. This finding is in accordance with our $a$ priori expectations Population density, PHP, though failed to reach the traditional level of significance, possesses a negative sign which is in accordance with our a priori expectations. The increasing population pressure on land encourages the agricultural labour force to move to urban areas and therefore, $R A L F$ declines. The variable $K A$ also possesses a positive sign and is highly statistically significant. This confirms the finding of Chaudhry (1980); Inukai (1984); Gotsch (1973) and Wizarat (1982) that technological progress in Pakistan has been labour augmenting in agricultural sector.

When $R A G$ is dropped from Equation (1) the results are reported in Equation (2).

$$
\begin{aligned}
R A L F= & \begin{array}{l}
0.47-0.61 P H P+0.000015 K A \\
(7.78)(7.77)^{*} \quad(3.98)^{*}
\end{array} \\
\bar{R}^{2}= & 0.76 F=41.11 \quad \text { D. } W .=1.40
\end{aligned}
$$

It may be seen that the coefficient of PHP is highly statistically significant with the negative sign. We also estimate Equation (1) by dropping $P H P$ variable and the results are reported in Equation (3).

$$
\begin{aligned}
& R A L F=0.16+0.61 R A G+0.000013 K A \\
& \text { (3.72) }(10.26)^{*} \quad(4.40)^{*} \\
& \bar{R}^{2}=0.85 F=76.57 \quad \text { D. } W .=1.62
\end{aligned}
$$

The coefficient of $R A G$ turns out to be highly statistically significant with a positive sign which substantiates our results obtained in Equations (1) and (3), respectively. Another important variable, the ratio of real wage in agriculture to real wage in manufacturing, $R A M$, possesses a negative sign but is statistically insignifcant which is due to a high correlation between $R A G$ and $R A M$ creating the problem of

* Statistically significant at 99 percent level of confidence.

**Statistically significant at 95 percent level of confidence. 
multicollinearity in Equation (4)

$$
\begin{aligned}
& R A L F=0.16+0.60 R A G-0.0022 R A M+0.000013 K A \\
& (3.00)(5.77)^{*} \quad(0.086) \quad(4.08)^{*} \\
& \bar{R}^{2}=0.85 \quad F=48.88 \quad \text { D. W. }=1.61
\end{aligned}
$$

This problem has been solved by dropping $R A G$ and the results are reported in Equation 5.

$$
\begin{aligned}
& R A L F=0.40-0.13 R A M+0.000016 K A \quad \ldots \quad \ldots \\
& \text { (0.17) (6.76)* (5.32)* } \\
& \bar{R}^{2}=0.76 F=43.25 \text { D. } W .=1.06
\end{aligned}
$$

The negative sign for the ratio of real wage in agriculture to the real wage in manufacturing suggests, that, if the real wage in agriculture rises at a faster rate than the real wage in manufacturing, the share of the agricultural labour force will decline in the total labour force. This finding is in accordance with the inverse relationship between the demand for labour and changes in the wage rate. The use of capital in agriculture, $K A$, in all the five equations remains positive and statistically significant thereby confirming that technological change in Pakistan has been labour augmenting rather than labour displacing.

\section{SUMMARY AND CONCLUSIONS}

The contention of this paper has been to undertake an econometric analysis of the determinants of the declining ratio of agricultural labour force to total labour force $(R A L F)$ in Pakistan using a time-series data for the period 1959-60 to 1986-87. The estimated results of the above analysis showed that population density (PHP) and the ratio of real wage in agriculture to real wage in manufacturing $(R A M)$ have a negative and significant impact on $(R A L F)$. It is also found that the share of agriculture in GDP $(R A G)$ representing economic development is an important explanatory variable in explaining the declining trend in $R A L F$. The major and interesting finding of this paper is that the use of capital in agriculture $(K A)$ representing technological progress has been labour augmenting rather than labour displacing in Pakistan's agriculture.

\section{REFERENCES}

Ahmed, B. (1972). "Farm Mechanization and Agricultural Development: A Case Study of the Pakistan Punjab”. Ph.D. Thesis, Michigan State University, USA.

Bose, S. R., and E. H. Clark (1969). "Some Basic Considerations on Agricultural Mechanization in West Pakistan". Pakistan Development Review. Vol. IX, No. 3.

Burney, Nadeem A. (1986). "Sources of Pakistan's Economic Growth". Pakistan Development Review. Vol. XXV, No. 4.

Chaudhry, M. Ghaffar (1980). "The Green Revolution and Income Inequality: Some Empirical Evidence from Rural Pakistan 1960-75”. (Unpublished Ph.D. Thesis) University of Wisconsin, USA.

Gotsch, Carl H. (1973). "Tractor Mechanization and Rural Development in Pakistan. International Labour Review. Vol. 107.

Pakistan, Government of (1987). The Pakistan Economic Survey, 1986-87. Islamabad: Economic Advisor's Wing, Ministry of Finance.

Inukai, I. (1984). "Farm Mechanization Output Labour Input: A Case Study of Thailand". International Labour Review. Vol. 101, No. 5.

Khan, M. J. (1975). "Economics of Farm Mechanization and Water Development Policies in Pakistan: A Case Study". Ph.D. Thesis, Colorado State University, USA.

Naqvi, Syed Nawab Haider, et al. (1983). The P.I.D.E. Macro-Econometric Model of Pakistan's Economy. Islamabad: Pakistan Institute of Development Economics.

Wizarat, Shahida (1982). "The Nature of Technological Change and Aggregate Production Function in Pakistan's Agriculture”. Islamabad: (Research Report Series, No. 137). 